\title{
Working
}

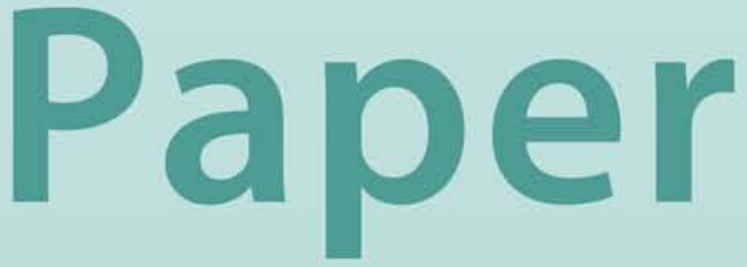


Issues in the Unification of Financial Sector Supervision

Richard K Abrams and Michael W. Taylor 


\title{
IMF Working Paper
}

Monetary and Exchange Affairs Department

\section{Issues in the Unification of Financial Sector Supervision}

\author{
Prepared by Richard K Abrams and Michael W. Taylor ${ }^{1}$ \\ Authorized for distribution by David S. Hoelscher
}

December 2000

\begin{abstract}
The views expressed in this Working Paper are those of the author(s) and do not necessarily represent those of the IMF or IMF policy. Working Papers describe research in progress by the author(s) and are published to elicit comments and to further debate.
\end{abstract}

The paper considers the generic arguments for and against the creation of a unified regulatory agency, covering each of the main types of financial institutions (banks, insurers and securities firms). The strongest arguments for unification are the enhanced oversight of financial conglomerates and the economies of scale they can potentially deliver. However, there are also a number of potentially serious disadvantages to unification, especially the risk that the change process will be mismanaged and will result in a reduction in regulatory capacity. The issue requires careful deliberation and ultimately depends on a matrix of factors which vary in importance from country to country.

JEL Classification Numbers:G18, G28, K20, L50

Keywords: financial services regulation, prudential supervision, regulatory agencies

Author’s E-Mail Address:rabrams@imf.org, mtaylor@imf.org

\footnotetext{
${ }^{1}$ Comments received from MAE staff including Michael Andrews, Udaibir Das, and V. Sundararajan are gratefully acknowledged.
} 


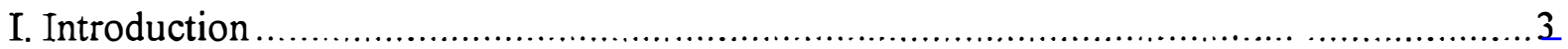

II. Prerequisites For Effective Supervision: A Summary .............................................5

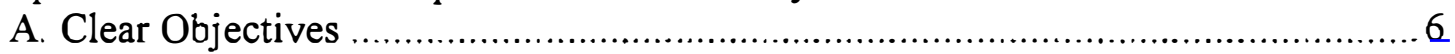

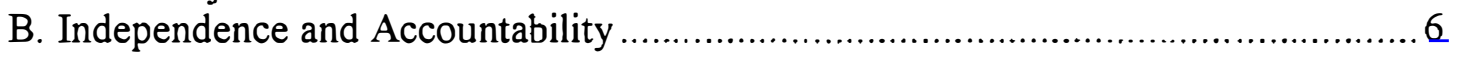

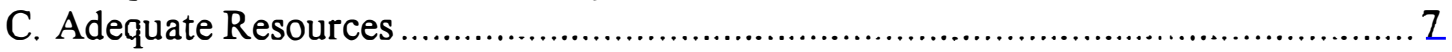

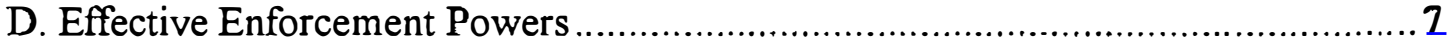

E. Comprehensiveness of Regulation ........................................................... 8

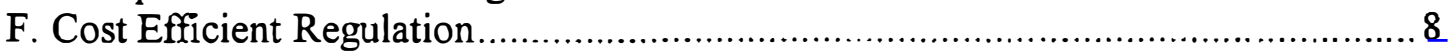

G. The Effectiveness Criteria and Industry Structure .................................. 8

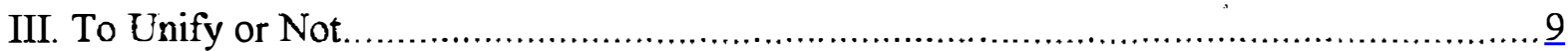

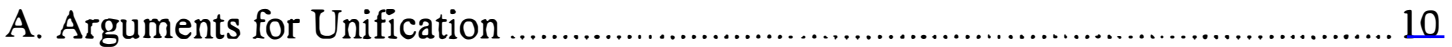

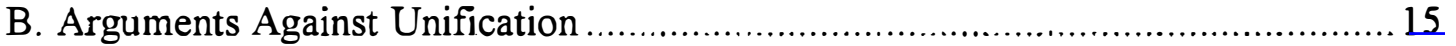

C. The Role of the Central Bank .......................................................... 19

IV. Alternatives to Full Unification ................................................................ 21

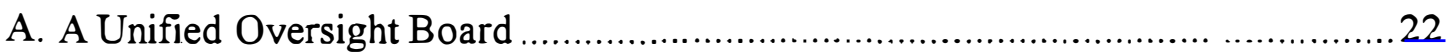

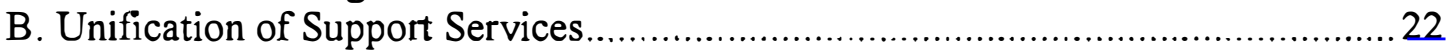

C. Share Facilities with the Central Bank ....................................................... 23

V. The Scope and Functions of a Unified Agency .............................................. 24

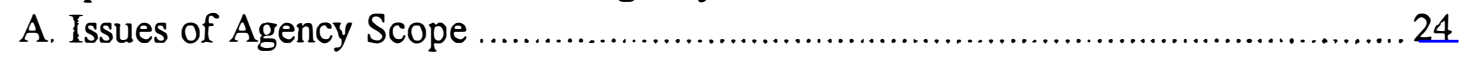

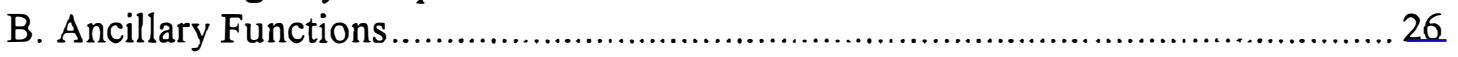

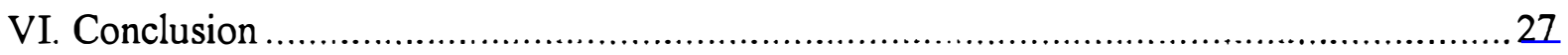

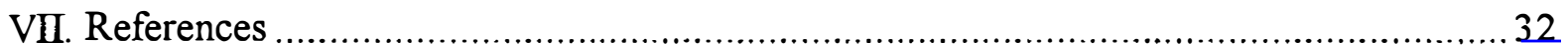

Text Table

1. The Regulatory Structures in Selected Countries ........................................... 4

Box

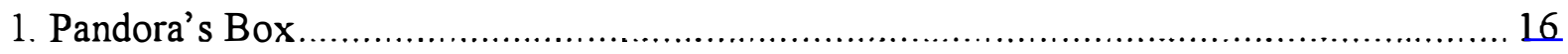

Appendix

Unification of Supervision: Checklist of Issues to Review.......................................29 


\section{INTRODUCTION}

Unified financial sector supervision--in which banking, ${ }^{2}$ insurance and securities regulation is combined in a single agency ${ }^{3}$-remains relatively rare in the world today. However, a number of countries have recently adopted this structure, giving rise to growing interest in the topic, particularly regarding the merits of such arrangements. In this regard, the appropriate regulatory structure appears to vary from country-to-country, and a major concern should be whether this type of financial regulatory structure is suitable to the individual circumstances of a particular country. This paper aims to provide a broad framework within which the arguments for and against unification can be analyzed and examined.

It should be stressed at the outset that changing the structure of regulation cannot of itself guarantee effective supervision. Institutional structure is a second order issue, to be considered once the various conditions for effective regulation, as discussed in the next section, are in place. Changing the structure of regulation might appear to answer to the desire to be seen to "do something"--especially in the aftermath of a financial crisis-but it will not necessarily address the root causes of the weaknesses of supervision that may have contributed to the crisis in the first place. ${ }^{4}$ Hence strengthening regulatory capacity needs to be given attention ahead of issues of the structure of regulation. Nevertheless, as will be discussed later in this paper, the unification of financial sector supervision can improve the efficiency and effectiveness of regulation in certain circumstances. For example, an integrated regulatory agency may be able to monitor the activities of integrated firms and markets more effectively than separate agencies, and thus may be an appropriate response, for example, to the formation of financial conglomerates. The central contention of this paper is that to be effective, the structure of the regulatory system needs to reflect the structure of the markets that are regulated. While appearing to provide a strong justification for unification in some circumstances, this factor is only one of several that needs to be taken into account; in some cases the balance of argument may tend to favor unification, whereas in others it will not.

\footnotetext{
${ }^{2}$ Throughout this paper we take "banks" and "banking" to refer to any institution that performs the payments system and intermediation functions of a bank whether or not it uses the word in its name.

${ }^{3}$ For the time being the issue of whether other parts of the financial sector (e.g., pension funds or finance houses) should also be included within the scope of a unified regulatory agency will be considered in Section $\mathrm{V}$ below.

${ }^{4}$ It may, however, assist in the elimination of gaps in regulatory coverage which in some circumstances may have contributed to the financial crisis in the first place, for example as the result of a systemically-significant unsupervised group of financial institutions.
} 
Perhaps reflecting the diversity of financial systems, as well as other factors like history and governmental institutions, regulatory structures vary widely. Nonetheless, in approximately half the countries contained in a recent study ${ }^{5}$ (see Table 1) the revealed preference is for a regulatory structure based on specialist agencies, with the banking, insurance, and securities sectors each supervised by a dedicated agency.

Table 1. The Regulatory Structures in Selected Countries

\begin{tabular}{lc}
\hline Separate agencies for each main sector & 35 \\
Combined securities and insurance regulators & 3 \\
Combined banking and securities regulators & 9 \\
Combined banking and insurance regulators & 13 \\
Unified supervision (in central bank) & 3 \\
Unified supervision (outside central bank) & 10 \\
\hline
\end{tabular}

Source: How Countries Supervise their Securities Markets,

Banks and Insurers (London: Central Banking Publications, 1999).

In most cases where the specialist agency model prevailed the banking supervisor was also the central bank. Nonetheless, this model is far from universal. In three countries (Chile, South Africa, and the Slovak Republic) the securities and insurance sectors have a common regulator, while banks are regulated by a specialist agency. In nine other countries banks and securities companies have the same regulator while insurance is regulated by a specialist agency. Both Germany and France have adopted a regulatory structure in which the prudential regulation of banks and securities firms is conducted by the same agency, while the oversight of securities markets is the responsibility of a specialist body; insurance companies are also supervised by a specialist regulator. In another thirteen countries banking and insurance regulation is combined while securities regulation is performed by a specialist agency.

As is shown in Table 1, the unified model is not as common as the recent attention it has received might seem to suggest. The ten countries classified as having adopted this organizational form are Australia, Canada, Denmark, Iceland, Japan, Norway, the Republic of Korea, Singapore, Sweden, and the United Kingdom. However, in at least two casesAustralia and Canada - the regulatory structure is not fully unified, as securities regulation is

${ }^{5}$ Llewellyn (1999). 
conducted separately from banking and insurance regulation. Moreover, in Singapore's case, regulation has been unified within the central bank. This leaves only seven countries that have fully unified regulatory agencies separate from the central bank. Over half of these are in the Nordic countries. This observation may suggest that unified supervision has, to date, been a response to country-specific factors, and as such may not be universally applicable. One aim of this paper is to consider this issue in some depth.

The structure of the rest of this paper is as follows. Section II provides a set of criteria for assessing regulatory arrangements, based on the standards set out in the Basel Core Principles and other relevant international standards and codes of good practice. Section III reviews the arguments for and against the unification of supervision in the light of these criteria. Section IV considers possible interim structures that might be used as an alternative to full unification in circumstances when it might be premature to adopt this model. Finally, Section $\mathrm{V}$ considers issues relating to the specific scope and functions of a unified authority, should the decision be taken to create one in a particular country. Appendix I presents a summary of the key issues raised in this paper.

\section{Prerequisites For EFFective Supervision: A Summary}

Maintaining and enhancing supervisory capacity and the effectiveness of supervision should be the primary goal of any proposed regulatory reform. As such the development of regulatory capacity should be given prominence over the issue of regulatory structure, and the latter is only a matter of fundamental concern to the extent that it can assist in achieving this overarching objective. In general, there are a number of essential prerequisites which any regulatory structure should meet if it is to have a reasonable likelihood of success. ${ }^{6}$ Furthermore, if these prerequisites are not met, steps should be taken to rectify these shortcomings before consideration is given to developing more complex forms of financial sector regulation, such as the development of a unified supervisory function. The following list does not aim to be exhaustive, but nonetheless attempts to provide an indicative set of key features that constitute an effective supervisory structure.

\footnotetext{
${ }^{6}$ Basel Committee (1997), Core Principle 1 states, "An effective system of banking supervision will have clear responsibilities and objectives for each agency involved in the supervision of banking organizations. Each such agency should possess operational independence and adequate resources. A suitable legal framework for banking supervision is also necessary, including provisions relating to authorization of banking organizations and their ongoing supervision; powers to address compliance with laws as well as safety and soundness concerns; and legal protection for supervisors. Arrangements for sharing information between supervisors and protecting the confidentiality of such information should be in place." While referring specifically to banking, the prerequisites identified in this Core Principle are equally applicable to the regulation of any financial institution or activity. The Code of Good Practices on Transparency of Monetary and Financial Policies ("Transparency Code") also contains a number of principles that are relevant to these issues.
} 


\section{A. Clear Objectives ${ }^{7}$}

A regulatory agency must have clear objectives, preferably set out in statute. Clear objectives assist the agency's senior management in making decisions on the efficient allocation of resources, and in determining the appropriate policy response to a given problem. Clear objectives can also help prevent regulation from expanding beyond the minimum necessary to correct the market failures which regulation is intended to correct (it should not become an unnecessary burden on the regulated institutions). Finally, they also provide a mechanism by which the regulatory agency can be held to account for its decisions and policies.

\section{B. Independence and Accountability}

A regulatory agency must be able to take decisions which belong to its sphere of competence without undue outside interference, whether it be from ministers, parliamentarians, industry leaders, or other government officials (including potentially central bankers). In this regard, it is especially important that senior management be protected from arbitrary removal. The rules governing the removal of senior management must therefore be transparent and demanding, ideally set out in an act of parliament. Budgetary autonomy, in the sense of the existence of an earmarked source of funding for the agency and its ability to allocate resources according to its own internal priorities, is equally important, for otherwise efforts to develop an aggressive and effective regulatory body can be stopped by cutting the agency's budget. Because of this, it is generally desirable that the regulatory agency be funded by a levy on regulated firms, rather than being dependant on allocations from the general government budget.

The need for regulatory independence should be balanced by a corresponding need to ensure that the agency can be held to account for its policies and actions. ${ }^{8}$ Accountability in the first instance needs to be to government and to parliament, since these are the sources of the agency's powers. However, responsiveness to the regulated industry may also need to be taken into account. This might, for example, be accomplished by creating a mechanism of formal consultation with representatives of these various groups. The statutory industry panel established as part of the UK's new regulatory arrangements provide one possible way in which these might be achieved. ${ }^{9}$ These types of accountability mechanism are especially

\footnotetext{
${ }^{7}$ See IMF (1999, called Transparency Code), Part V.

${ }^{8}$ Transparency Code, Part VIII.

${ }^{9}$ The Practitioner Panel was also established in November 1998, and is now placed on a statutory basis by the Financial Services and Markets Act. Its membership comprises senior representatives of the businesses that are regulated by the FSA. The Panel may make representations to the FSA, and the Act requires that the Authority "have regard" to such representations. By s.11, if the FSA disagrees with the view expressed or proposal made in
} 
important when the regulatory agency is funded by an industry levy, since it provides some means by which the industry can check and balance the regulator's power to raise funds and prevent the costs of regulation from becoming excessive. On the other hand, care needs to be taken that in introducing accountability to the industry the regulatory agency is not exposed to the risk of regulatory capture by the industry.

\section{Adequate Resources}

Allied to the funding issue is the consideration that the regulatory agency needs to have adequate resources to discharge its task effectively. Especially important is the ability to recruit, train, and retain a cadre of experienced professional staff. Since the kinds of skills required to make an effective regulator are also likely to be in heavy demand in the private sector, it follows that the regulator must be able to offer its staff competitive remuneration. (This is a further argument in favor of funding by an industry levy since it gives the regulator greater flexibility in remunerating its staff.) Similarly, the regulator must also be able to command adequate resources to ensure timely and effective data collection and processing.

\section{Effective Enforcement Powers}

A regulatory agency must possess effective enforcement powers over the full range of the firms it is responsible for regulating. These powers should include, as a minimum, the ability to require information from regulated firms, to assess the competence and probity of senior management and the owners of the institution, and to take appropriate graduated sanctions against failure to comply with regulatory rules, including having the ultimate power to intervene the institution if necessary. Ideally, the regulatory authority should have the ability to revoke licenses to conduct financial services business. However, in some countries this may not be compatible with constitutional provisions that require a strict separation of executive and judicial functions. In the latter case, the authority should have the ability to make recommendations on the revocation of licenses, with the decision-taker required to give reasons in the event that the authority's recommendation is not acted on. Enforcement powers are likely to remain more effective if the regulator has the ability to amend them quickly: for this reason it is generally preferable to set out only the broad framework of the regulatory agency's powers in legislation, leaving the details to be filled in by directives and guidelines that can be issued and amended by the regulatory agency itself. To effectively carry out their responsibilities, the staff of the regulatory agency should also have immunity from suit for actions taken in the discharge of their official duties.

the representation it must give the panel a statement in writing of its reasons for disagreeing, and this statement may be made public. 


\section{E. Comprehensiveness of Regulation}

Another essential feature of a regulatory system is that it should be comprehensive and free of regulatory gaps, i.e., there should be no scope for particular activities or types of intermediaries to escape effective regulation simply because there is doubt about which agency should be responsible for regulating it. A central component of comprehensiveness is that regulatory agencies should practice effective consolidated supervision of the institutions for which they are responsible. However, the case for comprehensiveness goes beyond this: all efforts should be made to eliminate gaps in the jurisdiction of the regulatory agencies, which could allow otherwise regulated activities or institutions to escape effective regulation. The regulators must also be in a position to respond quickly to market innovations to ensure that the regulatory framework remains up to date and does not become ineffective or acts as a barrier to the legitimate evolution of the market.

\section{F. Cost Efficient Regulation}

Regulation imposes costs both directly and indirectly. The direct costs are those needed to sustain the activities of the regulatory agencies: they include staff salaries, administrative overheads (including accommodation costs), and the information technology budget. The indirect costs of regulation are more difficult to quantify, but are those incurred by the regulated industry as a result of the need to comply with regulatory requirements. These costs can take many different forms, ranging from the costs of employing specialist "compliance" staff to the costs of maintaining special systems for regulatory reporting that go beyond those necessary for an institution's own internal purposes. As a general principle a regulatory arrangement with lower costs, both direct and indirect, is to be preferred to one which imposes higher costs.

\section{G. The Effectiveness Criteria and Industry Structure}

A key factor in a regulatory system's ability to meet the effectiveness criteria is that the institutional structure of regulation should reflect, at least to some degree, the structure of the industry it is called upon to regulate. Because industry structures vary markedly between countries, this implies that the regulatory structure will in turn need to exhibit a similar degree of variation. For this reason, no one type of regulatory structure will be optimal from the point of view of meeting the effectiveness criteria, and "one size fits all" solutions need to be avoided in this policy area as in any other.

For example, the case for combining banking and securities regulation is especially strong where the model of universal banking prevails. This is especially the case in those countries that have derived their supervisory frameworks from EU law. In addition to providing for the universal banking model, this framework also lays down a set of uniform capital rules, in the form of the Capital Adequacy Directive, that apply to the securities activities of both bank and nonbank financial institutions. Application of these rules by a single agency reduces the scope for competitive distortions and regulatory arbitrage opportunities. Moreover, a single agency is able to obtain oversight of all of a bank's 
activities, ensuring that risks arising from both its traditional banking activities and its activities in the securities markets are properly monitored and controlled. These considerations underlie the regulatory structures adopted in France and Germany, where the prudential regulation of banks and securities firms is conducted by the same agencies (the Commission Bancaire and the Bundesaufsichtsamt fur das Kreditwesen respectively).

A further reason for combining banking and securities regulation is that risks tend to arise on the assets side of the balance sheet. However, the case of insurance companies is somewhat different, since here the main financial risks occur on the liabilities side of the balance sheet (i.e., the primary risk is unanticipated claims by policyholders). In consequence, insurance supervision tends to be concerned about ensuring that the company maintains a sufficient stock of liquid assets (the "solvency margin") to meet claims that can be reasonably anticipated according to an actuarial assessment. Unlike credit or market risk, the scale of these risks tends to change relatively slowly over time. Because of these substantial differences between insurance, and banking or securities regulation, the case for a combination of all three functions is less clear cut. Nonetheless, in a number of countries, the decision to unify their supervisory functions has been taken because of the growth of financial groups, which own both banking and insurance businesses. ${ }^{10}$

These considerations imply that in some circumstances a regulatory system might be better able to meet the effectiveness criteria if it is unified. As will be discussed in the next section, where financial conglomerate groups form an important component of the financial system, a unified regulator might improve the comprehensiveness of regulation. In addition, through achieving economies of scale it might also reduce regulatory costs and make more efficient use of resources. However, there are a number of the essential prerequisites of regulation which unification in and of itself will not enhance, for example the effectiveness of regulatory powers and the independence and accountability of the agency. Much will depend on the way that unification is implemented and the way that the legislation is drafted; as will be shown in the next section, for every advantage that can be claimed for unification there is also a risk that needs to be balanced against it.

\section{TO UNIFY OR NoT}

The effectiveness criteria will now be used to examine the case for the unification of supervisory functions. The starting point is to consider the appropriateness of merging the three core financial sector supervisory functions into a dedicated agency or commission. In doing so, it is not only necessary to consider the advantages and disadvantages of such a change, but also whether alternative approaches can achieve the same results in a more efficient, or possibly safer, manner. It is also important to consider the implications that the decision to unify will have for the role of the central bank, and in particular whether or not it would be appropriate to separate the monetary policy and banking supervision functions.

${ }^{10}$ Sometimes referred to as "bancassurance" or "All-Finanz" groups. 
Finally, it is necessary to consider those circumstances when unification may not be appropriate

\section{A. Arguments for Unification}

A wide range of arguments have been advanced in favor of unification. ${ }^{11}$ Some of the most persuasive are based on efficiency grains, in particular the economies of scale, which seem to be offered by unification of supervisory agencies. However, some of the most prominent recent arguments are based on either the need to revise supervisory coverage in light of the rise of financial conglomerates or to ensure competitive neutrality in light of the blurring distinctions between the various classes of financial institutions. ${ }^{12}$ These latter arguments, which have been advanced in the context of a number of industrial countries, may not be as universally applicable as those based on regulatory efficiency.

\section{Supervision of financial conglomerates}

The rise of financial conglomerates, which operate diverse groups of financial institutions ${ }^{13}$ domestically, and often internationally as well, has led regulators to seek to identify ways to efficiently and effectively oversee their operations. Fragmented supervision may raise concerns about the ability of the financial sector supervisors to form an overall risk assessment of the institution on a consolidated basis, as well as their ability to ensure that supervision is seamless and free of gaps. There are also group-wide risks that may not be adequately addressed by specialist regulators, which have oversight jurisdiction over only part of a diversified conglomerate. Among these risks are whether the group as a whole has adequate capital and whether it has adequate systems and controls for managing its risks. Financial sector supervisors must also be able to ensure that they are able to respond on an institution-wide basis should serious problems occur in any part of the conglomerate. Experience has shown that, while these firms generally claim to have financial firewalls between their various operations, they are often proven to be largely illusory when serious difficulties arise.

Ensuring effective supervision of diversified financial conglomerate groups places several requirements on the various financial supervisory bodies that are not usually present in more simple corporate structures. First, the supervisory bodies must have an effective and efficient system of rapidly sharing information with each other on each particular institution;

${ }^{11}$ See Briault (1999) for a full discussion.

${ }^{12}$ This literature is relatively extensive, given that the subject of regulatory structure has otherwise been under-researched. First to make this argument were Borio and Filosa (1994). Their work has been followed by Goodhart (1995), Taylor (1995), and Goodhart et al (1998).

13 These groups combine at least two of the activities of banking, insurance, and securities. 
while also ensuring the appropriate degree of confidentiality. Second, the supervisory bodies must have a close and ongoing working relationship to ensure that suspicions and findings are fully and promptly shared, and that regulatory gaps are identified and closed. Third, and most importantly, steps should be taken to ensure that, for each institution, one supervisory agency is given the power, authority, and responsibility to take the lead in both forming an overall risk assessment and to lead the regulatory response, should problems arise; this agency is generally referred to as the lead regulator.

Financial institutions also seek to minimize the burden of supervision by demanding that supervision of their operations be carried out as efficiently and with as little duplication as possible. For conglomerates, this requires that some attempt be made to address the additional burden associated with fragmented supervision. This can be done by minimizing overlap and duplication in reporting and oversight, and by simplifying the process of seeking decisions on the part of the regulator. Having a single contact point for all requests on regulatory issues may allow regulators to respond more rapidly and flexibly, while reducing the risk of regulatory gaps developing.

Although it might be possible for a series of specialist regulators to cooperate in the supervision of a diversified financial group, for example, by using the lead regulator arrangement, a unified approach seems nonetheless to offer a better prospect of coordination and the exchange of information than would occur between separate agencies. ${ }^{14}$ It can be argued that a unified supervisory function is best suited to deal with all of the above problems, for by placing all the financial sector supervisors for a given conglomerate under a single agency, one creates a single management structure that should be able to instruct-and if need be to force the various operating divisions to closely cooperate and share information as it becomes available. Furthermore, cooperation in closing regulatory gaps and eliminating regulatory overlap can be more easily effected, as can binding decisions regarding the assignment of a lead regulator. Such an arrangement may also aid international cooperation, because foreign supervisors will be given a single contact point for all regulatory issues.

\section{Competitive neutrality}

A related argument is based on the fact that the lines of demarcation between products and institutions have blurred as financial systems have evolved and matured. Thus, the situation may arise where financial institutions offering similar services or products are supervised by different authorities. In this case, there is a strong likelihood that there will be differences in their regulation and the associated costs of achieving compliance, which may, in turn, give certain institutions a competitive advantage in offering a particular service or product.

${ }^{14}$ Achieving agreement on assigning a lead regulator has proved remarkably difficult in practice. 
The existence of a range of supervisory authorities also poses the risk that financial firms will engage in some form of supervisory arbitrage. This can involve the placement of a particular financial service or product in that part of a given financial conglomerate where the supervisory costs are the lowest or where supervisory oversight is the least intrusive. It may also lead firms to design new financial institutions or redesign existing ones strictly to minimize or avoid supervisory oversight. If such attempts at regulatory arbitrage become widespread, these efforts may have second round effects in which the various supervisory authorities "compete" to reduce the burden of their oversight in order to avoid a flight of their "clients" to other supervisory agencies. While some such competition is conceivably healthy, there is the risk that the authorities may allow prudential supervision to be weakened. A unified supervisory function is well-designed to deal with all of the above-noted problems, for a single supervisory body is better able to iron out differences and inconsistencies, whatever their source. Having a single management structure directly overseeing all supervisory bodies is also probably the most effective way to ensure that the various bodies do not compete for customers.

On the other hand, complete regulatory neutrality should not be a primary objective of supervision. One of the main objectives of financial sector supervision is minimizing the risk of systemic difficulties. Thus, the potential social costs associated with financial difficulties in a participant in the payments system, whose failure might give rise to systemic problems, are very different than those associated with the failure of a mutual fund or a finance company. Accordingly, the optimal amount of oversight of a similar operation may vary markedly between different types of institutions. Thus, while supervisors may wish to closely examine a bank's activities in a potentially risky market, e.g., stock market derivatives, its attitudes toward the same operations being carried out by a mutual fund would be very different. Given these differences, supervisors can argue that it is proper to supervise the same operation differently depending on the nature of the institution in which carrying out the transaction. Thus, to a degree, supervisors should encourage a certain amount of regulatory arbitrage, insofar as it involves locating riskier operations in subsidiaries that are outside of the systemically important part of the conglomerate. Of course, if the conglomerate's firewalls are inadequate, this approach may be self-defeating.

\section{Regulatory flexibility}

A potential advantage of the unified approach to supervision is that it may allow for the development of regulatory arrangements that are more flexible than can be achieved with separate specialist agencies. Whereas the effectiveness of a system of separate agencies can be impeded by "turf wars" or a desire to "pass the buck," these problems can be more easily limited and controlled in a unified regulatory organization. Specialist agencies can also be impeded from operating effectively where their respective enabling statutes leave doubts about their jurisdiction or locus for dealing with a particular matter, especially when a new type of financial product or institution emerges, which was not covered by the original legislation. As a result, a unified agency may offer a more effective way of responding to market developments or innovations. 
While flexibility is useful in the context of the developed financial markets, where the rapid pace of financial innovation rapidly leads to the obsolescence of regulations and rules, it is also desirable in emerging and transition economies as well. For countries which have recently liberalized their financial systems often experience a process of rapid industry change, which may include the growth of certain types of nonbank financial intermediaries which can pose a significant threat to financial sector soundness. ${ }^{15}$ Thus, having a regulatory agency with the scope and capacity to respond rapidly to these changes by extending its regulatory jurisdiction is a major benefit of a properly constituted unified agency. However, achieving this objective requires that the enabling statute for the unified agency be drafted with sufficient flexibility to permit it to rapidly respond to market innovations. If the range of products and institutions subject to regulation is too narrowly defined in the legislation, or the legislation cannot be amended quickly, then the benefits of a unified approach versus a set of separate agencies will be more limited.

\section{Regulatory efficiency}

Although scale economies are difficult to measure in a regulatory organization, as a matter of general principle, a larger size of organization permits finer specialization of labor and a more intensive utilization of inputs. In a regulatory context, unification may permit cost savings on the basis of shared infrastructure, administration, and support systems. The existence of multiple, specialized regulatory bodies, has generally resulted in the duplication of support infrastructures, for example, in data collection and processing, and personnel administration. These are areas where there would appear to have been significant scope for cost savings and economies of scale from unification. Unification may also permit the acquisition of information technologies, which become cost-effective only beyond a certain scale of operations and can avoid wasteful duplication of research and information-gathering efforts. A more unified approach to data collection may also lay the basis for a more efficient reporting system, which could result in significant cost savings for the regulated enterprises, particularly financial conglomerates. On the other hand, as discussed below, there are also important synergies between the data necessary for banking supervision and for monetary policy purposes which may outweigh the synergies between the data required for banking supervision and for the regulation of other financial intermediaries. Which factor should be given greatest weight to a large extent will depend on the structure of the financial system; one in which financial conglomerates form a significant element will probably benefit to a greater extent from combining the data collection effort for all types of financial institution.

The absence of hard data makes it difficult to assess the strength of the economies of scale argument, although it is worth noting that in all of the Scandinavian countries-which were the first to establish this type of regulatory agency - it is believed that the approach has made it possible to realize significant scale economies (Taylor and Fleming, 1999). Britain's Financial Services Authority (FSA) has also reported substantial savings from the unification

\footnotetext{
${ }^{15}$ Particularly when they are formed to evade effective supervision.
} 
of support services. In most cases, the supervised institutions also seem to take the view that unification has eliminated unnecessary duplication and overlap (Briault, 1999).

The economies of scale arguments is most applicable in countries where supervisory agencies tend to be small, notably in small countries or those with small financial systems. In these countries, the benefits of merging the administrative and data processing functions of the various supervisory functions are difficult to dismiss. Such overheads can constitute a heavy cost for such functions, and the economies of scale in sharing these services can be great, particularly if the supervisory functions do not share these functions with some other larger institutions, such as the central bank or the finance ministry. In fact, one former head of a unified supervision function viewed this as the strongest argument for unification. On the other hand, similar benefits may be gained by having the supervisory functions share such services individually or as a group, even though they remain independent from one another in their management and all of their other operations. This approach may be taken a step further by having the supervision function(s) effectively subcontract administrative and EDP services from a larger body such as the central bank. This option is discussed in more detail in the following section.

\section{Developing a body of professional staff}

An essential requirement of effective regulation is that a regulatory agency should be able to attract, retain, and develop a body of skilled professional staff. Unification can assist in this process, especially in those countries where regulatory capacity is still being developed. As a single larger employer of financial regulators, a unified agency might be better placed to formulate a coherent human resources policy, including a career planning strategy for its personnel. It would be able to offer its staff a more varied and challenging career than they would enjoy in a specialist regulator, and might be sufficiently large to develop its own tailored, in-house training programs.

Unification also makes it easier for supervisors to share specialized knowledge. First, it could allow supervisors for one group of financial institutions to borrow a specialist from another group, or even to hire a single specialist to support several different supervisory functions. Second, it may lay the basis for efficiency gains by having supervisors work together on issues of mutual interest, either with respect to particular financial conglomerates or on regulatory and reporting issues in general. Third, this arrangement may also help preserve scarce management skills, for in many countries finding a sufficient number of capable managers to lead their supervisory functions is problematic.

The shortage of supervisory resources is a serious problem in a number of countries, most notably in the Baltic States, Russia and the Other Republics of the Former Soviet Union (BRO). But while most are clearly applicable in small countries or smaller financial systems, this argument also applies in larger financial markets as well, especially in those areas where developments in regulatory techniques have required regulators to recruit and retain human resources with highly marketable skills. Given that the public sector always has difficulties in 
competing with the private sector for these skills, one of the attractions of unification is that it enables these scarce human resources to be deployed to their greatest effect.

\section{Improved accountability}

A final argument in favor of unification is that it improves the accountability of regulation. Under a system of multiple regulatory agencies, it may be more difficult to hold regulators to account for their performance against their statutory objectives, for the costs of regulation, for their disciplinary policies, and for regulatory failures. The existence of multiple agencies, perhaps with overlapping responsibilities and areas of jurisdiction, makes possible a blame disbursement strategy among the regulators, thus making it difficult to hold any of them accountable. One advantage of a unified agency is that by creating a single management structure, it should be clear to politicians, the industry, and the public who should be held to account for particular regulatory actions or failures.

On the other hand, the relationship between unification and improved accountability is essentially second-order. A unified agency might still be difficult to hold to account if its objectives are ill-defined; while multiple specialist agencies might be more easily held to account if their objectives are clearly specified. Hence, the fundamental consideration should be the clarity of regulatory objectives rather than the number of agencies involved in regulation.

\section{B. Arguments Against Unification}

Not surprisingly, the list of arguments against unification is almost as long as the list of arguments in favor of unification. These include claims that unification will result in unclear objectives for the regulatory agency; economies of scope will prove hard to achieve as long as banking, securities and insurance business is subject to different regulations; the agency will suffer from diseconomies of scale; and that it will extend moral hazard concerns across the whole financial services sector. There is also the concern that the change process itself may be poorly managed or become politicized. As a result, it will be subject to unpredictable and possibly undesirable outcomes (see Box 1). 


\section{Box 1. Pandora's Box}

A serious disadvantage of a decision to create a unified supervisory agency can be the unpredictability of the change process itself. This risk has a number of different dimensions.

The first risk is that opening the issue for discussion will set in place a chain of events that will lead to the creation of a unified agency, whether or not it is appropriate to create one. The problem is one of political power: powerful actors within the government and the public sector may see such a proposal as an opportunity to increase their influence within government by taking on important additional powers. Furthermore, the individuals that see themselves best placed to lead the unified agency, will tend to push the issue aggressively and seek to rush the proposal through parliament quickly, before the internal balance of power shifts against them. In such circumstances, there is clearly a risk that mistakes will be made in the design of the agency, and that the plan may be pushed forward even if it appears likely that the unified authority will be sufficiently flawed as to make its creation inadvisable. If the process of creation becomes tied into an internal battle for power, it would also increase the risk that the unified agency will have insufficient autonomy, or worse be highly politicized.

The second risk is legislative. The creation of a unified agency will generally require new legislation, but this creates the possibility that the process will be captured by special interests. As a result, issues, which had previousiy been thought settled under existing financial services legislation-for example, decisions on the scope of activities subject to regulation or the appropriateness of exemptions from regulation-may be reopened. Thus, depending on the balance of parliamentary forces the legislative outcome may be weaker than the original legislation under which the separate regulatory agencies had been established. One way to minimize this risk is to limit the need for legislation to a simple enabling act. This would establish the unified agency, and effect a transfer of powers to it from the existing regulatory bodies, while leaving existing statutes otherwise unaffected. However, this minimalist approach has its disadvantages. One is that it does not permit the harmonization of legislation across the different financial services sectors, which is one of the primary advantages of regulatory unification. Another is that it may also fail to address the issue of regulatory gaps. It also does nothing to reduce the risks that the reorganization will result in a power grab that will undermine the autonomy of the individual agencies.

The third risk created by the change process is a possible reduction in regulatory capacity through the loss of key personnel. Many of the staff will view the unification process change with trepidation, while others may see this a difficult and trying period, which they would prefer to avoid. Thus, many staff who would be important or valuable members of the new organization may view this as a time to test the job market or retire. This has been a serious problem during the formation of a number of unified agencies, with staff turnover in some cases reaching unsustainable levels. It is likely to be compounded in the event that the change involves extraction of banking supervision from the central bank. Many of the best bank supervisors may prefer either to remain with the central bank or to move into the private sector rather than risk the perceived reduction in pay and/or status, which joining a specialist regulatory body would involve. Thus, there is a real risk that many seasoned workers and highly qualified professionals may be lost; a very serious consideration if the supervisory function is not particularly strong or wellstaffed. On the positive side, this is also a time when it may be particularly easy to weed out the weaker, less skilled staff within the old function.

The fourth risk is that the change management process itself will go off track. The process of creating a unified regulatory agency places heavy demands on management resources, often in environments where such resources are already in short supply. The management challenge of putting together a number of disparate regulatory agencies should not be underestimated, and there will be a need for a well-conceived and carefully monitored change management program to make it effective. During the transition process itself, this risk may be addressed by ensuring that the new supervisor body has-or hires-experts with the skills to bring about such a reorganization in an efficient, cost effective manner. However, the management issues, which will arise in the early years of the unified agency, cannot be dealt with in a similar way and are for the agency's own management itself to address. 


\section{Unclear objectives}

One of the most powerful arguments advanced against unified regulatory agencies is that it will be difficult for them to strike an appropriate balance between the different objectives of regulation. Given the diversity of these objectives-ranging from guarding against systemic risk to protecting the individual consumer from fraud--it is possible that a single regulator might not have a clear focus on the objectives and rationale of regulation, and might not be able to adequately differentiate between different types of institutions. Indeed, rather than improving accountability, the creation of a unified regulator might diminish it because of the difficulty of designing a single set of objectives for it. As a result, its statutory responsibilities may be vague and ill-defined, which in turn can give rise to problems of holding the regulatory agency to account for its activities. Vague objectives may also provide little guidance for the regulator when (as inevitably will be the case) its different objectives come into conflict. Specialist agencies with a clear focus on a specific regulatory objective are arguably both more easily held to account for their actions and less likely to extend regulation inappropriately. ${ }^{16}$

\section{Diseconomies of scale}

Despite the strength of the economies of scale argument in favor of unified regulation, it has to be recognized that a single unified regulator may also suffer from some diseconomies of scale. One source of inefficiency could arise because a unified agency is effectively a regulatory monopoly, which may give rise to the type of $X$-inefficiencies usually associated with monopolies. A particular concern about a monopoly regulator is that the new function could be more rigid and bureaucratic than separate specialist agencies. This view is based on the premise that the larger the organization the more bureaucratic it is likely to be, particularly if its operations become so broad-based that the line managers are unable to fully understand the range of operations of the organization. However, this issue is more likely to hinge on the organization and management of the function than on its size. If the supervisory body is poorly managed, staffed or organized, it is likely to be inflexible and bureaucratic whether it is large or small. It must not be forgotten that a unified function in a small country may still be smaller than each of the main supervisory bodies in a large country, and that many large countries have efficient and flexible financial sector supervisors.

Another source of diseconomies of scale is the tendency for unified agencies to be assigned an ever-increasing range of functions; sometimes called the "Christmas-tree effect." This may arise because the formation of a unified agency may tempt politicians and policymakers to require it to perform tasks, which may be only tangentially connected to its core functions. For example, in some Scandinavian countries, unified agencies have been required to take on the regulation of real estate brokers, although this arguably detracts from their primary function. Similarly, the U.K.'s FSA has already been the subject of several

${ }^{16}$ See Taylor (1997) for elaboration of this point. 
attempts to assign it new responsibilities which are beyond its already broad scope. These include the regulation of mortgages (on consumer protection grounds) and encouraging competition in the financial services industry.

\section{Limited synergies}

Some critics of unification argue that the synergy gains from unification will not be very large; in other words, economies of scope are likely to be much less significant than economies of scale. In this regard, it is true that the cultures, focus, and skills of the various supervisors vary markedly. For example, it has been noted that the sources of risks at banks are on the asset side, while most of the risks at insurance companies are on the liability side. Furthermore, the behavior of the various types of supervisors vary markedly, with some describing banking supervisors as being more like doctors examining the health of the patient, while securities supervisors are more like policemen trying to catch the miscreant securities dealers. ${ }^{17}$ The evidence of unified authorities to date tends to suggest that even within a single organization these differences of style and culture will remain, and trying to create a single agency culture has been one of the most difficult tasks for management. To some extent the difficulty has been compounded_or at least not assuaged-by the fact that the internal organization of these agencies has tended to mirror traditional institutional lines-i.e., most have been established with separate departments for banking, securities, and insurance regulation. However, this is now changing, as some authorities are beginning to experiment more with matrix-based organizations, for example the Complex Groups division of the FSA, which specializes in the supervision of financial conglomerates. However, while there is a consensus that efficiency gains from unification can be substantial, the evidence to date that the unified agencies can achieve significant synergies between their different functions is mixed, and difficult to quantify.

\section{Moral hazard}

Perhaps the most worrisome of all the criticisms of unified regulation is the "moral hazard" argument. This argument is based on the premise that the public will tend to assume that all creditors of institutions supervised by a given supervisor will receive equal protection. Hence if depositors, and perhaps other creditors, are protected from loss in the event of bank failure, then the customers and creditors of all other financial institutions supervised by the same regulatory authority may expect to be treated in an equivalent manner. Clearly this is an informational problem, and in the event of unification, the new supervisory body will need to clarify the rules of the game regarding the treatment of the

${ }^{17}$ It may also be significant that international cooperation also tends to occur on institutional lines and in this respect the work of the Joint Forum is the exception rather than the rule. 
various financial institutions. ${ }^{18}$ Furthermore, it may be necessary for the supervisor to reinforce its position by treating any nonbank institutions that get into trouble strictly according to the pre-announced rules of the game.

\section{The Role of the Central Bank}

A further dimension to the arguments for and against unification is the extent to which the central bank is, or should be, directly involved in banking supervision. The earliest examples of unified supervision, in Denmark, Norway, and Sweden, were established in systems where the central bank had not been the banking supervisor. This state of affairs remains exceptional in most of the rest of the world. Thus, in many countries, the decision to . create a unified supervisory agency will probably necessitate the extraction of banking supervision from the central bank, as has occurred recently in Australia and the United Kingdom. Although an alternative possibility would be to combine all supervision within the central bank, as practiced in Singapore, moral hazard considerations may weigh heavily against this structure. (This option is discussed in more depth later in this section.) For the purposes of the present discussion, it will be assumed that the unification of supervision will involve the separation of the banking supervision and monetary policy functions. This requires some consideration of the arguments for and against the combination and separation of monetary policy and banking supervision within the central bank.

The arguments for and against the separation between supervision and monetary policy have been well examined (Goodhart and Schoenmaker, 1995). The arguments against separation are strong. In particular, since banks are the conduit through which changes in short-term interest rates are transmitted to the wider economy, the central bank needs to be concerned about their financial soundness as a precondition for an effective monetary policy. This argument is reinforced by a number of others, including: the synergies between the information required for the conduct of monetary policy on the one hand and the supervision of the banking sector on the other; the central bank's need to assess the creditworthiness of participants in the payments system, which will inevitably involve it in forming judgements about the solvency and prudent conduct of banks; and the central bank's need to have access to information on the solvency and liquidity of individual banks in order to exercise its lender of last resort functions. These arguments have traditionally been seen as making a powerful case for combining the banking supervision and monetary policy functions, and their strength is attested to by the fact that, as was discussed in the introduction, the practice in many countries remains for the central bank to be responsible for banking supervision.

In addition to these arguments, it is also possible to cite a number of operational considerations in favor of combination. First, the economies of scale obtained from the combination of monetary policy and banking supervision may be as substantial as those that arise from combining the regulation of the different financial sectors. The commonalties in

${ }^{18}$ In such circumstances, constructive ambiguity may not be all that constructive. 
the information requirements for these respective functions have already been mentioned. In addition, to the extent that there is an overlap in the knowledge and skills required for these different functions, then a central bank may enjoy a comparative advantage in recruiting and - retaining the best staff. This argument is particularly strong in countries where the absolute level of human capital with this skill is very small.

Another important consideration, especially in the countries of the BRO, is that in many central banks now have a strong guarantee of their independence, sometimes even written into constitutional law. This degree of independence, established primarily for the purposes of ensuring a credible monetary policy, can also help to shield banking supervision from undue parliamentary or ministerial influence. Thus in transitional or emerging market economies there may be a case for retaining banking supervision within the central bank not only on the traditional grounds cited above, but also out of a concern to avoid the politicization of bank regulation.

On the other hand, it may be possible to develop governance and funding arrangements for the unified regulator that give it adequate political autonomy. Moreover, it should be borne in mind that there are several general arguments for the separation of banking supervision and monetary policy, irrespective of whether or not the separation arises out of the unification of supervision. First, a central bank, which is also responsible for supervision, may err on the side of laxity if it fears that tight monetary conditions may lead to bank failures. ${ }^{19}$ Secondly, bank failures inevitably will occur and when they do they will be blamed on the supervisor. If the supervisor is the central bank its credibility will be undermined, and with it its credibility in the conduct of monetary policy. In addition, it has also been argued that changes in payment system technology, most notably the move to real-time-gross settlement (RTGS), changes of the nature of the oversight the central bank needs to exercise over participants in the system. ${ }^{20}$ Finally, as the financial system becomes less bank-centered, and more dominated by financial conglomerate groups with banking as only one of their financial services activities, the moral hazard issues discussed above gain increased significance, and these may point to the need for a regulatory structure with comparative distance between the central bank-as provider of lender of last resort assistance-and the agency responsible for routine supervision and regulation.

${ }^{19}$ However, as Goodhart and Schoenmaker argue, the validity of this argument is to a large degree dependent on the structure of the banking and financial system; the greater that the system involves intermediaries financing maturity mismatch positions through the wholesale markets the greater the potential for conflict between monetary and financial stability goals.

${ }^{20}$ While RTGS system and other institutional arrangements to control risk may act to decrease systemic risks, issues relating to the increased complexity and opacity of settlement arrangements pose a new set of concerns for the supervisor. (Financial Sector Inquiry: Final Report (1997), p. 377). 
So far the discussion has concerned only the combination of banking supervision with monetary policy within the central bank. However, another option in structuring regulation would be to combine a wider range of regulatory functions within the central bank. Thus the central bank might be responsible for supervising the securities markets as well as banks, and possibly even insurance companies as well. This arrangement is likely to seem particularly attractive in some of quite specific circumstances: first, when the financial sector, and especially the non-bank financial sector is relatively small, making it difficult to establish viable regulatory agencies outside the central bank; secondly, where banking is the main form of financial intermediation, and other financial sectors are dominated by groups with a bank at their head; thirdly, where the central bank has a strong competitive advantage in attracting staff with the right skills and credentials, for example where central bank salaries are significantly above those available for other public officials; and finally, where the central bank has strong guarantees of its independence, thus providing a defense against the politicization of regulation. In circumstances where all, or most, of these conditions prevail, the option of centralizing all regulatory functions within the central bank may seem to have much to commend it.

However, this option also suffers from a number of serious disadvantages. Clearly, the moral hazard problem will be even more pronounced if the unified supervisory function is conducted by the central bank itself. It may be difficult for a central bank, which also supervises a wide range of financial intermediaries to make sufficiently clear the differentiation between them. Thus it may give rise to a perception in the public mind that all types of financial contract will receive the same degree of protection in the event of firm failures. While it may be possible for the authorities, through a campaign of public education, to explain the different levels of protection available to the holders of different type of financial claim, their attempts to do so may be undermined by the perception that holders of all financial claims will enjoy the prospect of central bank support.

A second difficulty is that this approach might be perceived as granting the central bank excessive powers. If all regulatory functions are combined within the central bank, this will result in the central bank having responsibility for the conduct of monetary policy and the regulation of all financial intermediaries, both banks and nonbanks. A related problem is the risk that particular regulatory failures may tarnish its reputation and credibility, especially in its conduct of monetary policy. Both of these objections might be minimized in the event that the supervisory function remains a legally independent agency albeit one located within the central bank. But if this is done, it will be important to ensure that the supervisory agency is able to establish a distinct identity of its own in the public mind.

\section{ALTERNATIVES TO FULL UNIFICATION}

If on the balance of the argument seems to favor a unified approach to financial sector supervision, but the necessary pre-conditions for successful unification are not in place, it may be worth considering whether other institutional arrangements might be feasible, at least as an interim solution, and possibly as a long-term alternative to unification as well. This might avoid the need for wholesale reform of the financial regulatory structure, and thus 
avoid some of the risks identified in "Pandora's Box," while still achieving some of the advantages of a unified authority. There are a number of possible variations on this

minimalist approach, which include the use of an oversight board, and sharing facilities either on a stand-alone basis or with the central bank.

\section{A. A Unified Oversight Board}

The most limited option would be to leave the existing regulatory structure in place, but to overlay it with a newly established oversight board. The board could be formed from the heads of the various regulatory agencies, or it could be widened to include third parties, such as representatives of the ministry of finance and the central bank. Depending on its terms of reference, the board might provide either a forum for expediting communication and information sharing between the agencies or it could be charged with executive decisionmaking, including the setting of policy. An important function of this body could be to coordinate regulatory efforts, e.g., by arranging joint inspection visits. (A possible model is represented by board created in South Africa as an alternative to regulatory unification).

An oversight board provides a more formalized basis for coordinating the supervision of financial conglomerates than a lead regulator arrangement, but it does not eliminate problems that can occur from differences in regulations, rulebooks and enforcement powers. It may also provide an opportunity for the regulatory agencies to gain some experience working together with a view to facilitating their unification at some point in the future. Since it leaves in place all of the existing regulatory system, it does not require major new legislation or a far-reaching change management process. However, the modest ambitions of this approach may also be its greatest weaknesses. The chairmanship of the oversight board could, depending on its functions, be a key position, which will therefore generate rivalry between the heads of the regulatory agencies, and if the board is broadened to allow for an outside leader, political disputes and power plays could easily emerge. Furthermore, this approach is not appropriate when significant economies of scale may be possible. In view of these considerations the oversight board approach is most appropriate for comparatively large financial markets in which conglomerates are an important component of the financial system, but where the overall market size is sufficient to support a number of specialist regulators.

\section{B. Unification of Support Services}

One way to achieve economies of scale without unification would be to keep the agencies as separate legal entities, but to locate them in the same building with shared infrastructure and support services. An oversight board structure could also be included to give overall direction to the separate agencies and to ensure that they coordinate their efforts; alternatively, a centralized management structure could be developed as an administrative rather than legislative matter. The physical proximity of regulatory staff may also encourage greater informal information sharing and coordination. 
Such an arrangement could be continued indefinitely or used as a prelude to eventual formal unification. It could be relatively quick and easy to implement, although finding an appropriate building to house all of the regulatory agencies might take time. ${ }^{21}$ On the other hand, it appears to offer many of the advantages of unification without some of the associated costs, and it avoids the risk that new legislation might result in a suboptimal outcome. Its primary disadvantage is that the absence of a strong central management authority might lead to rivalries and unresolved tensions between the senior staff of the different agencies. ${ }^{22}$ This arrangement may also not be well-designed to deal with financial conglomerates. For though administratively unified, the different agencies would continue to operate under different statutes, rule books, and would exercise different powers. Hence, consistent treatment of diversified financial groups might be hard to achieve.

This approach would therefore seem best suited to countries with small financial sectors in which financial conglomerates are not a significant presence. In such cases, this approach would allow them to achieve the economies of scale without running the risks associated with more fundamental change. However, in those cases where banking supervision is currently conducted by the central bank, this may not be a feasible option, since, as noted earlier, removing the banking supervision function from the central bank-in fact if not in law-would be likely to result in the problems of staff retention and a reduction of regulatory capacity.

\section{Share Facilities with the Central Bank}

The above-noted problem might be avoided if the regulatory agencies were to share the central bank's facilities. One option, discussed in the previous section, would be to make the central bank responsible for the supervision of all financial intermediaries. However, an alternative approach would be to establish the supervisory agency as a separate legal entity, but one that shares the support services of the central bank, as was done in Finland. ${ }^{23}$

${ }^{21}$ This has been a problem in Latvia, for example, where locating suitable accommodation for the unified agency has contributed to delays in implementation.

${ }^{22}$ This outcome was avoided in the U.K. because a new centralized management structure was implemented in advance of the new legislation.

${ }^{23}$ The Finnish Financial Supervisory Authority is responsible for the supervision of banks and securities companies. Insurance company regulation is combined with the regulation of private sector pension funds in a separate authority. This arrangement reflects the relative unimportance of financial conglomerates in Finland compared with other Nordic countries. See Taylor and Fleming (1999) for further discussion. 
The Finnish approach has two main attractions. First, it allows for the realization of significant economies of scale, comparable—or perhaps greater-than those that might be expected from a stand-alone unified supervisory agency. Second, this arrangement may actually prove superior to a stand-alone agency for crisis management. If the supervisory agency shares the same premises and IT systems as the central bank, and its staff are also employees of the central bank (as is the case in Finland), then information flows and coordinated action in the event of a crisis should be facilitated. This was a major factor behind Finland's decision to adopt this approach.

The primary disadvantage of this approach is moral hazard. As noted previously, one of the most serious objections to unification within the central bank is that it might extend the " perceived central bank guarantee of support to all financial institutions, including nonbanks. Hence, if a unified supervisory agency is located within the central bank, even while remaining legally distinct, there is a risk that the public and industry perception will be that the two institutions are in fact the same, which may, in turn, encourage the view that central bank support will be available to all supervised institutions.

\section{THE SCOPE AND FUnCTIONS OF A UNIFIED AGENCY}

A further issue to be considered if the balance of argument favors the creation of a unified authority, is its precise scope and functions.

\section{A. Issues of Agency Scope}

A fundamental issue is whether the unified agency should be responsible for both prudential (safety and soundness) and consumer protection (business conduct) regulation. Most integrated agencies are concerned only with ensuring the prudential soundness of financial intermediaries. The United Kingdom's FSA is practically unique among unified authorities in being responsible for both prudential and business conduct matters.

There are arguments both for and against the separation of prudential and business conduct objectives. Arguments in favor of separation are that the skills sets required of prudential and conduct of business regulators are different. ${ }^{24}$ Moreover, separation also allows the agency charged with prudential oversight to focus more explicitly on the detection and management of risks to the financial system. The ability to adopt a narrow focus is especially important in countries, which are prone to periods of financial instability. Furthermore, consumer protection regulation tends to be relatively resource-intensive. As a result, taking on the broader mandate may actually act to undercut a supervisory authority's efforts to establish a system of effective prudential regulation, particularly in smaller and developing countries.

${ }^{24}$ This argument was influential with the Australian Wallis inquiry which decided against establishing a single regulator for the financial sector. See Commonwealth of Australia Financial System Inquiry: Final Report (1997). 
On the other hand, defenders of a combined function argue that there are several regulatory judgements _especially relating to the adequacy of systems and controls and the fitness and probity of management - which overlap in the two functions (Briault, 1999). It should be noted, however, that the degree of overlap may not be particularly extensive, and in most countries it has not been regarded as a sufficiently strong reason to bring consumer protection within the unified agency's scope. Prudential and conduct of business regulation are most frequently combined in securities regulation, whereas in banking and insurance regulation it has been the general practice to keep the two functions clearly separate. If a unified regulator is to focus only on prudential regulation, this raises the issue of where responsibility for the securities regulator's business conduct functions is to be assigned.

This consideration also leads to the further question of whether the unified agency should be responsible for regulating markets - e.g., the stock market or futures exchange-as well as intermediaries. One solution might be to combine the business conduct and market oversight functions within a specialist agency, leaving the unified regulator to focus only on prudential matters. ${ }^{25}$ The skills required to ensure that a market meets standards for transparency and trade reporting, and that it is not subject to manipulation, are similar to those required for business conduct regulation, while in turn being somewhat different from those that are normally needed for effective prudential regulation. On the other hand, the activities of securities and investment firms may be difficult to monitor without access to the type of information which the market oversight function will normally provide, although close cooperation and coordination between the relevant agencies should minimize this problem.

A final set of issues relates to the types of nonbank financial intermediaries that should come within the integrated agency's scope. One issue which frequently arises is the whether the unified agency should regulate pension funds. Defined contribution schemes are usually provided by investment management companies, and therefore it might be a natural extension of the agency's functions to bring them within its scope. By contrast, defined benefit schemes raise issues similar to those that arise in assessing the solvency of insurance companies and, indeed, are often provided by those companies. Actuarial assumptions are the most important factor in the assessment of the balance sheets of both insurance companies

${ }^{25}$ This arrangement has not been widely adopted although the regulatory structures in France, Germany and Italy reflect it to some degree (prudential regulation in those countries not being fully unified). Thus in France, the Commission Bancaire is the prudential supervisor of banks and securities firms, but the Commission des Operations de Bourse (COB) is the market surveillance regulator. The Australian approach deals with the issue in a different way, by combining prudential regulation in respect of banks and insurance companies in the Australian Prudential Regulatory Authority (APRA). The Australian Securities and Investments Commission (ASIC) is responsible for all aspects of securities regulation: prudential, business conduct, market integrity, and disclosure by listed companies. 
and defined benefit pension funds, which also share in common the need for a long-term asset structure combined with short-term liquidity requirements. Hence there is a strong case for combining the regulation of defined benefit pension funds with that of insurance companies.

Other nonbank financial intermediaries that might potentially come within the scope of a unified agency include finance houses and leasing companies. In many jurisdictions these types of companies are not subject to regulation. However, their role in initiating a number of financial crises raises the question whether the unified authority should at least have the power to require them to provide it with information on request. On the other hand, when considering which nonbank financial intermediaries to include within a unified agency's scope, it is worth bearing in mind that over-extending the scope of the supervisory authority may blur its focus and seriously erode its effectiveness. Moreover, the case for explicitly including these types of institutions within the agency's scope only arises if they are not covered by the consolidated supervision of banks and other regulated entities. Provided that the regulatory agency conducts effective consolidated supervision, many of the systemic risks arising from this sector will be contained.

\section{B. Ancillary Functions}

In addition to the above array of functions, unified agencies may also be asked to take on a number of functions that are either ancillary to their primary functions or do not directly relate to the regulation of financial markets and institutions. One such function concerns the setting of accounting standards, or at least the oversight of the professional body responsible for setting them. In some jurisdictions, for example in the United States, the capital markets regulator (SEC) is responsible for overseeing accounting standards that apply to publicly listed companies. Consequently, in countries where the capital markets authority has been modeled on the SEC, one result of unification may be that the new agency will acquire this role from its predecessor agency. On the other hand, while it can be helpful for the regulatory agency to have responsibility for the accounting standards which apply to regulated institutions (especially banks), there is no necessary connection between prudential soundness regulation and oversight of accounting and auditing firms. Hence it would appear generally preferable for this function to be transferred elsewhere. Similarly, the extent to which the unified agency becomes involved in the implementation of Stock Exchange listing requirements will depend partly on the pre-existing scope of the capital markets regulator.

Competition policy is another function that is peripheral to the primary responsibilities of a financial regulator. In most jurisdictions, it is normal for competition in the financial sector to be subject to the general rules on industrial competition and, hence, to be under the jurisdiction of a specialist competition authority. However, in some countries, an argument has been advanced that the financial sector regulator should also have an obligation to promote competition within its sector. This point of view has been urged in particular in the U.K., where some have argued that the FSA should have this obligation incorporated in its statutory duties. However, this argument is made largely on consumer protection grounds, since competition is seen as a partial substitute for sales practice 
regulation. Where the unified regulator has a specifically prudential scope, this question is unlikely to arise.

\section{CONCLUSION}

The main conclusion of this review of the issues raised by the unification of financial sector supervision is that no one model of regulatory structure will be appropriate for all countries. While fully unified supervisory agencies - those regulating banking, insurance, and securities—do offer certain advantages over separate agencies, the advantages appear to vary sharply between countries. Moreover, they must also be weighed against the disadvantages, the strength of which will also vary considerably from case to case. The same points apply to the other regulatory structures considered in this paper. Hence, in each case, it is essential to first perform a full assessment of the advantages and disadvantages of applying a particular model developed in one member country to the conditions of another.

The assessment of advantages and disadvantages should take into account two overarching factors. The first is that any change process involves risks, and the greater the proposed structural change the greater will be the risks. Many of these risks are examined in "Pandora's Box," but perhaps the most important single factor is that the change process may result in a serious reduction in existing regulatory capacity unless it is well-managed. ${ }^{26}$ This concern is particularly great with respect to banking supervision, which is the key supervisory function in many developing and transition economies given the centrality of banks to their financial systems. In these countries, great care will need to be exercised to ensure that banking supervisory capacity is not compromised by unification. Another important factor is the need to preserve (or enhance) the independence of the regulatory agency. If a proposal to create a unified authority threatens either agency capacity or independence then it is probably not worth undertaking. In any case, the benefits of change should be relatively clear and unambiguous before embarking on a proposed unification. Where the evidence of the benefits of unification is more ambiguous, or the costs of change may be high, more modest institutional innovations should be considered, ranging from the formation of a unified oversight board to shared facilities with the central bank.

The second overarching factor is that the institutional structure of regulation should reflect the institutional structure of the industry it is designed to regulate. For example, the combination of banking and securities regulation is most clearly appropriate where the system comprises universal banks. In countries where banks are not significant players in the securities markets, the case for a combination of function is much less strong. Similarly, the combination of banking and insurance regulation is most appropriate where linkages between banks and insurance companies are particularly significant. Combining the regulation of all three sectors within a single agency will, therefore, be most appropriate when the financial

${ }^{26}$ This is likely to be a particular concern in transition or developing economies where regulatory capacity may, in any case, be already relatively weak. 
services industry of the country comprises a number of diversified, multi-activity groups or where the distinctions between different types of financial intermediaries have become blurred. In the latter case, a strictly institutional approach to regulation may no longer adequately reflect the distribution of risk in the financial system.

These various factors suggest that it will be important to differentiate the staff recommendations according to the stage of development of the financial market and its degree of complexity. Moreover, the question of regulatory structure should be seen not as an end in itself-regulatory structure by itself is not the primary issue-but as a possible means, together with other measures, to achieving the primary objective: the provision of effective supervision, by a well-staffed, well-resourced, and independent regulatory agency. A welldesigned regulatory structure that is appropriate for the conditions of a particular country's financial sector, can deliver many benefits. 


\section{Unification of Supervision: Key Issues}

Prerequisites for effective supervision (If not in place, unification may not be a priority.)

- Are supervisory objectives clear and preferably set out in statute?

- Do supervisory authorities have adequate political independence?

- Do supervisory authorities have adequate budgetary independence, including access to sufficient human resources?

- Are supervisory authorities subject to sufficient degree of accountability?

- Is the regulatory framework comprehensive?

- Do supervisory authorities have appropriate range of enforcement powers (graduated corrective action)?

- Can and do the supervisory authorities make appropriate use of their enforcement powers?

Regulatory framework

- Are there serious regulatory gaps or excessive areas of regulatory overlap?

- If financial conglomerates are important:

a) Is supervision conducted on a consolidated basis?

b) Is regulatory arbitrage a problem or likely to become one?

c) Are their clear lines of accountability for and between the supervisory authorities?

d) Is coordination and cooperation between supervisory agencies a problem?

e) Are there agreements regarding the "lead" regulator in the event of financial difficulties in a conglomerate?

- Is the system able to quickly respond to financial innovations?

Structure of financial system

- Is banking sector dominant?

- Is a universal banking model used?

- Do financial conglomerates play a major role in the system? 
- Has there been or is there likely to be a blurring of distinctions between the classes of financial institutions (notably the financial products offered)?

- Are capital markets well developed?

- Is the financial sector being liberalized or rapidly transformed?

Issues relating to the Central Bank

- Is the banking supervision function located in the Central Bank?

- If so, the Central Bank credible and does it have stature?

- If banking supervision is moved out of the Central Bank, is there a serious risk that its political or budgetary autonomy will be compromised?

Regulatory efficiency

- Is it likely that significant economies of scale can be achieved through unification (particularly avoiding wasteful duplication of functions and resources)?

- Do there appear to be significant synergies to having multiple supervisory agencies under a single roof (such as sharing expensive and specialized experts or making better use of scarce resources)?

- Is the regulation cost effective?

Likelihood of unpredictable or undesirable outcome (Pandora's box)

- Will opening this issue result in a pressures to create a unified agency whether or not such an agency is found useful?

a) Will the unified agency be created as more of a tool to enhance some individual(s) political power than because it's formation is really appropriate?

b) Might the above-noted pressures result in the legislation being rushed through the Parliament even if the legislation is not well thought out and designed?

- Could political pressures undermine the budgetary or financial independence of the new agency or in some other way cause it to be weaker than the ones it replaces?

- Is there a risk that the formation of the new agency could result in a sufficiently large loss of key staff that regulatory capacity might be undermined? Is there a real risk that poor management of the change aggravate these problems? 
Scope and function of agency

- Which types of financial institutions share a common ownership? (Also see the section on the structure of the financial system.)

- Are other nonbank financial institutions important in the financial sector?

a) Are most of the major nonbank institutions part of financial conglomerates and (effectively) supervised on a consolidated basis?

b) Would the unified supervisory authority have the resources to effectively supervise these institutions? 


\section{REFERENCES}

Basle Committee on Banking Supervision, 1997, Core Principles for Effective Banking Supervision, Basel Committee on Banking Supervision, No. 30, September (Basle: Bank for International Settlements).

Borio, C.E.V., and R. Filosa, 1994, "The Changing Borders of Banking: Trends and Implications," BIS Economic Paper, No.43, December (Basle: Bank for International Settlements).

Briaut, Clive, 1999, The Rationale for a Single National Financial Services Regulator, Financial Services Authority, Occasional Paper No.2 (London: Financial Services Authority).

Financial System Inquiry: Final Report, 1997 (Canberra: Commonwealth of Australia).

Goodhart, C.A.E., 1995, "Some Regulatory Concerns," London School of Economics Financial Markets Group, Special Paper, No.79, December.

D. T. Llewellyn, P. Hartmann, L. Rojas-Suarez, and S. Weisbrod, 1998, Financial Regulation: Why, How and Where Now? (London and New York: Routledge).

, and D. Schoenmaker, 1995, "Institutional Separation between Supervisory and Monetary Agencies" in C.A.E. Goodhart, The Central Bank and the Financial System (Cambridge, Massachusetts: MTT Press).

International Monetary Fund, 1999, Code of Good Practices on Transparency in Monetary and Financial Policies, September (Washington, D.C.: International Monetary Fund).

Llewellyn, D.T.,1999, "Introduction: The Institutional Structure of Regulatory Agencies" in How Countries Supervise Their Banks, Insurers and Securities Markets, (London: Central Banking Publications).

Taylor, M., 1995, Twin Peaks: A Regulatory Structure for the New Century, December (London: Centre for the Study of Financial Innovation).

— 1997, Regulatory Leviathan: Will Super-SIB Work? (London: CTA Financial Publishing). European Experience," World Bank Policy Research Paper No. 2223, November (Washington: World Bank). 